\title{
Evaluation of Free Radical Scavenging Activities and Phytochemical Screening of Curcuma longa Extracts
}

\author{
Nachimuthu Maithilikarpagaselvi ${ }^{1,2}$, Magadi Gopalakrishna Sridhar ${ }^{1,3 *}$, Ramalingam Sripradha ${ }^{1,4}$ \\ 'Department of Biochemistry, Jawaharlal Institute of Postgraduate Medical Education and Research, Pondicherry, INDIA. \\ 2Department of Biochemistry, All India Institute of Medical Sciences, Jodhpur, Rajasthan, INDIA. \\ ${ }^{3}$ Department of Biochemistry, KMCH Institute of Health Sciences and Research, Coimbatore, Tamil Nadu, INDIA. \\ ${ }^{4}$ Department of Biochemistry, Shri Sathya Sai Medical College and Research Institute, Chennai, Tamil Nadu, INDIA
}

\begin{abstract}
Objectives: The study investigated the free radical scavenging and antioxidant potential of the methanol, ethanol and ethyl acetate extracts of turmeric rhizome. Methods: We assessed the phytochemical constituents, total polyphenol and flavonoid content in these turmeric extracts using standard phytochemical analyses. Phytochemical screening of turmeric extracts showed the presence of carbohydrates, proteins, sterols, tannins, flavonoids and saponins. Results: Ethanol extracts showed the highest polyphenol content $(71.7 \pm 3.0 \mathrm{mg}$ of gallic acid equivalents/g of extract) and flavonoid content $(28.5 \pm 2.1 \mathrm{mg}$ quercetin equivalents $/ \mathrm{g}$ of extract) when compared to other extracts of turmeric rhizome. Similarly, ethanol extract of turmeric possessed the higher antioxidant activity (463.25 \pm $36.15 \mu \mathrm{M} \mathrm{Fe}(\mathrm{II}) / \mathrm{g}$ of extract) in FRAP assay. The inhibitory concentration $\left(E C_{50}\right)$ of gallic acid, ethanol, methanol and ethyl acetate extract were found to be $27 \mu \mathrm{g}, 30 \mu \mathrm{g}, 38 \mu \mathrm{g}$ and $47 \mu \mathrm{g}$ respectively in DPPH assay. The $\mathrm{H}_{2} \mathrm{O}_{2}$ scavenging activity of the extract $(20,40,50,100$ and $200 \mathrm{~g} / \mathrm{ml})$ was increased in a dose dependent manner and ethanol extracts found superior hydrogen peroxide scavenging activity similar to gallic acid standard. The curcuminoids (standard) and the turmeric extracts were separated in
\end{abstract}

Thin layer Chromotography (TLC). The Curcuminoids were separated into curcumin, dimethoxycurcumin, bis demethoxycurcumin with $R_{f}$ value of $0.91,0.65$ and 0.44 respectively. The composition of turmeric extracts was consistent with the composition of curcuminiods as shown by the $R$ values. Conclusion: The study concludes that ethanol extract of turmeric showed high polyphenol and flavonoid content which is attributed to its higher anti-oxidant properties.

Key words: Turmeric, Phenolic content, Flavonoids, Ferric reducing antioxidant power assay, DPPH radical scavenging assay.

Correspondence

Dr. Magadi Gopalakrishna Sridhar

Professor and Head, Department of Biochemistry, $\mathrm{KMCH}$ Institute of Health Sciences and Research, Coimbatore-641046, Tamil Nadu, INDIA.

Phone: +919442262333

Email: sridhar_biochem@yahoo.co.in

DOI: 10.5530/jyp.2020.12.23

\section{INTRODUCTION}

Turmeric (Curcuma longa) is a rhizomatous plant of the ginger family, Zingiberaceae and commonly found in southeast tropical Asia. The root of this plant i.e., rhizome is used for culinary and medicinal purposes. It is widely used as spice, colouring and flavouring agent in food preparations especially in Southeast Asia. It has been used as home remedy for various illnesses such as common cold, sore throat, fever, biliary disorders, anorexia, wounds and sinusitis. The yellow-pigmented fraction of turmeric is attributed due to the presence of phytochemicals called curcuminiods. Curcumin I (1,7-bis (4-hydroxy-3-methoxyphenol)-1,6heptadiene-3, 5-dione) is the major active component present in turmeric and is responsible for most of its biological activities. The anti-oxidant potential of curcumin is owing to the presence of hydroxyl group on the phenyl ring. ${ }^{1}$ Curcumin is a polyphenol and is lipophillic in nature, hence insoluble in water and ether but soluble in ethanol, dimethylsulfoxide and other organic solvents. ${ }^{2}$ The other constituents present in turmeric are volatile oils including tumerone, atlantone and zingiberone and sugars, proteins and resins. Due to the presence of curcumin and other constituents turmeric is widely used as a medicine for the treatment of many ailments. It is vastly used as an anti-inflammatory agent. ${ }^{3}$

Extensive studies carried out by researchers around the globe have clearly demonstrated curcumin's potential as a therapeutic agent and have paved the way towards conducting clinical trials for various diseases including cancer, cardiovascular, neurological and gastrointestinal disorders, multiple sclerosis, type II diabetes, skin diseases, cystic fibrosis, cataract etc. ${ }^{4}$ Hence, in the present study, we aimed to evaluate the free radical scavenging and antioxidant potential of methanol, ethanol and ethyl acetate extracts of turmeric rhizome.

\section{MATERIALS AND METHODS}

\section{Chemicals}

Curcuminoid and 2,2-diphenyl-1-picrylhydrazyl (DPPH), were purchased from Sigma Co. (St. Louis, MO, USA). 2, 4, 6-tripyridyl-striazine (TPTZ) and ferrous sulphate were procured from Himedia, Mumbai. All other chemicals were of analytical grade obtained from SRL (India).

\section{Preparation of turmeric extracts}

Turmeric rhizomes were obtained from local market. The rhizomes were identified and authenticated as Curcuma longa by the French Institute of Pondicherry, Puducherry, India (HIPF 26738). Rhizomes were cleaned with water, dried and grounded into a fine powder. The powdered samples were added to conical flasks containing ethanol, methanol and ethyl acetate in the ratio of 1:10. The samples were kept in shaking water bath for $24 \mathrm{hr}$. The extraction mixtures were separated from the residue by centrifuging at $1500 \mathrm{rpm}$. Supernatants were evaporated to dryness under vacuum at $40^{\circ} \mathrm{C}$ using rotary evaporator. The obtained extracts were kept in sterile sample tubes and stored in refrigerator at $4^{\circ} \mathrm{C}$. 


\section{Preliminary phytochemical screening}

The phytochemical constituents such as carbohydrates, proteins, sterols, tannins, flavonoids and saponins were analyzed qualitatively using standard procedures. ${ }^{5}$ The assays were repeated thrice under same conditions on three consecutive days.

\section{Estimation of total phenols}

The total phenolic content of turmeric extracts was estimated with FolinCiocalteu reagent using the method of Singleton and Rossi et al. ${ }^{6} 100 \mu \mathrm{l}$ of the turmeric extract solution $(1 \mathrm{mg} / \mathrm{ml})$ was added to $750 \mu \mathrm{l}$ of FolinCiocalteu reagent $\left(1: 10\right.$ diluted with distilled water) and kept at $22^{\circ} \mathrm{C}$ for five minutes. To this, $750 \mu \mathrm{l}$ of $6 \%$ sodium carbonate was added, mixed and kept in dark for $90 \mathrm{~min}$ at $22^{\circ} \mathrm{C}$. The solution was measured at 725 $\mathrm{nm}$ and the results were obtained from a standard graph of Gallic acid $(0-0.1 \mathrm{mg} / \mathrm{ml})$. The values were expressed as $\mathrm{mg}$ of gallic acid equivalents (GAE)/g of turmeric extract. The assay was repeated thrice under same conditions for three consecutive days and the mean value was obtained.

\section{Estimation of total flavonoids}

The total flavonoid content of three different extracts was determined using the aluminium chloride colorimetry assay. ${ }^{7}$ One $\mathrm{ml}$ of extract $(1 \mathrm{mg} / \mathrm{ml})$ or standard solutions of gallic acid $(20,40,60,80$ and $100 \mu \mathrm{g} /$ $\mathrm{ml}$ ) was added to a $10 \mathrm{ml}$ volumetric flask containing $4 \mathrm{ml}$ of distilled water. And then $0.3 \mathrm{ml}$ of $5 \%$ sodium nitrite was added and mixed well. The reaction mixture was incubated for $5 \mathrm{~min}$ at $37^{\circ} \mathrm{C}$. To this, $0.3 \mathrm{ml}$ of $10 \% \mathrm{AlCl}_{3}$ and $2 \mathrm{ml}$ of $1 \mathrm{M} \mathrm{NaOH}$ was added and the volume was made up to $10 \mathrm{ml}$ with distilled water. The solution was mixed and absorbance was measured at $510 \mathrm{~nm}$ against blank in UV-Visible spectrophotometer. The total flavonoid content was expressed as mg of gallic acid equivalents (GAE).

\section{Hydrogen peroxide scavenging activity}

The hydrogen peroxide-scavenging ability of the turmeric extracts was determined by the method of Bozin et al. ${ }^{8}$ Different concentrations of turmeric extracts and gallic acid standards from 20 to $100 \mu \mathrm{g} / \mathrm{ml}$ were prepared freshly. One milliliter of extract or gallic acid standard was mixed with $2.4 \mathrm{ml}$ of phosphate buffer $(0.1 \mathrm{M}, \mathrm{pH} 7.4)$ and $0.6 \mathrm{ml}$ of $\mathrm{H}_{2} \mathrm{O}_{2}$ $(40 \mathrm{mM})$ solution. The solution was mixed thoroughly and incubated at room temperature for $10 \mathrm{~min}$. The absorbance of the solution was measured at $230 \mathrm{~nm}$ against blank solution containing the turmeric extracts without $\mathrm{H}_{2} \mathrm{O}_{2}$. The percentage inhibition of turmeric extracts and standards were calculated using the following formula.

Percentage scavenged $\left[\mathrm{H}_{2} \mathrm{O}_{2}\right](\%)=\mathrm{Abs}$ (control)- Abs(extract/ standard)]/ Abs(control) X 100

where, Abs(control) was the absorbance of the control (without extracts or standard)

Abs(extract/standard) was the absorbance in the presence of the extracts or standard

\section{2, 2-Diphenyl-1-Picrylhydrazyl (DPPH) assay}

The free radical scavenging activity of extract was measured according to the method of Brand-Williams et al. ${ }^{9}$ by decrease in the absorbance of methanol solution of DPPH. Different concentrations of turmeric extracts and gallic acid standards (20 to $100 \mu \mathrm{g} / \mathrm{ml})$ were prepared freshly. The stock solution of $0.3 \mathrm{mM} \mathrm{DPPH}$ was prepared in methanol and kept at $20^{\circ} \mathrm{C}$ until analysis. $3 \mathrm{ml}$ of DPPH solution was mixed with $1 \mathrm{ml}$ of aqueous turmeric extracts and standards. The solutions were mixed well and kept in the dark for $30 \mathrm{~min}$. The control was prepared by mixing $2 \mathrm{ml}$ of DPPH and $1 \mathrm{ml}$ of methanol and kept at dark for $30 \mathrm{~min}$. The absorbance was measured at $517 \mathrm{~nm}$ using microplate reader spectrophotometers. Samples were measured in three replicates. Percentage of DPPH scavenging activity was calculated as \% inhibition of DPPH $=$ [Abs control -Abs sample / Abs control $] \times 100$.

\section{Total antioxidant activity (FRAP ASSAY)}

Total anti-oxidant activity (FRAP assay) was estimated according to the method of Benzie and Strain. ${ }^{10}$ FRAP working solution was prepared by adding $25 \mathrm{ml}$ of $0.3 \mathrm{M}$ acetate buffer, $2.5 \mathrm{ml}$ of $10 \mathrm{mM}$ TPTZ and $2.5 \mathrm{ml}$ of $20 \mathrm{mmol} \mathrm{FeCl}_{3} .6 \mathrm{H}_{2}$ o solution. The working solution was prepared freshly. $3 \mathrm{~mL}$ of working FRAP reagent was mixed with $100 \mu \mathrm{L}$ of turmeric extracts and incubated at room temperature for $4 \mathrm{~min}$. The absorbance was measured at $593 \mathrm{~nm}$ using UV/visible spectrophotometer. Results were obtained from a standard graph of $\mathrm{Fe}_{2} \mathrm{SO} 4(0-1000 \mu \mathrm{Mol} / \mathrm{L})$ and expressed as $\mu \mathrm{M}$ FRAP Fe(II)/g of extracts.

\section{Separation of turmeric extracts and curcuminoids by Thin layer chromatography (TLC)}

Turmeric extracts were separated by thin layer chromatography. Samples and curcuminoid standards were prepared by diluting in respective solvents. About $5 \mu \mathrm{l}$ of samples and standards were applied to the origins of a TLC pre-coated silica gel plate $2 \mathrm{~cm}$ above the bottom with the help of capillary tube. After the application of the sample, the plates were kept in a glass chamber which was saturated with mobile phase (Chloroform: methanol, 95: 5) for $20 \mathrm{~min}$. The mobile phase was allowed to move through the stationary phase up to $3 / 4^{\text {th }}$ of the plate. The plate should be removed from the chamber before the solvent front reaches the top of the stationary phase and dried. After drying, the plates were kept in the chamber saturated with iodine vapours for detecting the spots. All plates were visualized with the help of UV light at $254 \mathrm{~nm}$ and $366 \mathrm{~nm}$ in UV TLC viewer for detecting the additional spots. The Retention factor $\left(\mathrm{R}_{f}\right)$ value of the different spots were calculated using the following formula.

$$
\mathrm{R}_{f}=\frac{\text { Distance travelled by substance (turmeric extract) }}{\text { Total distance travelled by Mobile phase }}
$$

\section{Statistical analysis}

All the assays were repeated thrice under the same conditions for three consecutive days and the mean value was obtained. The results were expressed as the mean \pm SD. Data were analyzed using SPSS (Statistical Packages for Social Science, version 16.0). All data were analysed by ANOVA followed by Tukey post hoc test. $P<0.05$ was considered as statistically significant.

\section{RESULTS}

Table 1 shows the Preliminary phytochemical analyses of turmeric extracts. Methanol, ethanol and ethyl acetate extracts shows the presence of Sterols, Alkaloids, Flavonoids and Phenols. Tannin was present in both methanol and ethanol extracts but absent in ethyl acetate extract.

Table 2 shows the extraction yield, total phenol and flavonoid content of three different turmeric extracts. The percentage yield of methanol, ethanol and ethyl acetate was 10.0, 10.4 and 9.7 respectively. Total phenolic content and total flavonoid content were determined from the calibration curves of gallic acid and quercetin respectively. It was found that ethanol extract has the highest phenol content $71.7 \pm 3.0 \mathrm{mg}$ of gallic acid equivalents (GAE)/g of extract and flavonoid content $28.5 \pm 2.1 \mathrm{mg}$ quercetin equivalents $(\mathrm{QE}) / \mathrm{g}$ of extract followed by methanol and ethyl acetate extracts. The phenolic content of methanol and ethyl acetate extract was $52.1 \pm 3.8$ and $49.2 \pm 2.8 \mathrm{GAE} / \mathrm{g}$ of extract and flavonoid content was $24.2 \pm 4.8$ and $21.8 \pm 3.7 \mathrm{QE} / \mathrm{g}$ of extract respectively.

Figure 1 shows the total anti-oxidant activity of three different turmeric extracts. The anti-oxidant activity was determined by FRAP. The results 
indicated that ethanol extract of turmeric exhibited significantly $(P<$ $0.05)$ higher antioxidant activity $(463.3 \pm 36.2 \mu \mathrm{M} \mathrm{Fe}$ (II)/g of extract) when compared to methanol $(346.53 \pm 25.75 \mu \mathrm{M}$ Fe (II)/g) and ethyl acetate extract $408.7 \pm 53.1 \mu \mathrm{mol} \mathrm{Fe}(\mathrm{II}) / \mathrm{g}$ of extract.

Table 1: Preliminary phytochemical analyses of turmeric extracts.

\begin{tabular}{cccc} 
Phytochemical compounds & $\begin{array}{c}\text { Methanol } \\
\text { Extract }\end{array}$ & $\begin{array}{c}\text { Ethanol } \\
\text { Extract }\end{array}$ & $\begin{array}{c}\text { Ethylacetate } \\
\text { Extract }\end{array}$ \\
\hline Carbohydrates & - & - & - \\
Proteins & - & - & - \\
Sterols & + & + & + \\
Tannins & + & + & - \\
Alkaloids & + & + & + \\
Flavonoids & + & + & + \\
Phenols & + & + & + \\
Steriods & - & - & - \\
Glycosides & + & + & + \\
\hline
\end{tabular}

+ Present, - Absent

Table 2: Extraction yield and total amount of plant phenolic compounds, flavonoids of three different turmeric extracts.

\begin{tabular}{cccc}
$\begin{array}{c}\text { Turmeric } \\
\text { extracts }\end{array}$ & $\begin{array}{c}\text { Yield } \\
(\%)\end{array}$ & $\begin{array}{c}\text { Total Phenol } \\
\text { content (mg of gallic } \\
\text { acid equivalent } \\
\text { (GAE)/g of extracts) }\end{array}$ & $\begin{array}{c}\text { Total flavinoid } \\
\text { content (mg of } \\
\text { quercetin equivalent } \\
\text { (QE)/g of extracts) }\end{array}$ \\
\hline $\begin{array}{c}\text { Methanol Extracts } \\
\text { Ethanol extracts } \\
\text { Ethylacetate } \\
\text { extracts }\end{array}$ & $10.0 \mathrm{~g}$ & $52.1 \pm 3.8$ & $24.2 \pm 4.8$ \\
\hline
\end{tabular}

$\mathrm{a}=$ when compared to methanol extracts,

$\mathrm{b}=$ when compared to ethanol extracts,

Results expressed as mean \pm standard deviation, $(n=3)$. All data were analyzed by ANOVA followed by Tukey post hoc test. $P<0.05$ was considered as statistically significant.

GAE: Gallic acid equivalent, QE: quercetin equivalent.

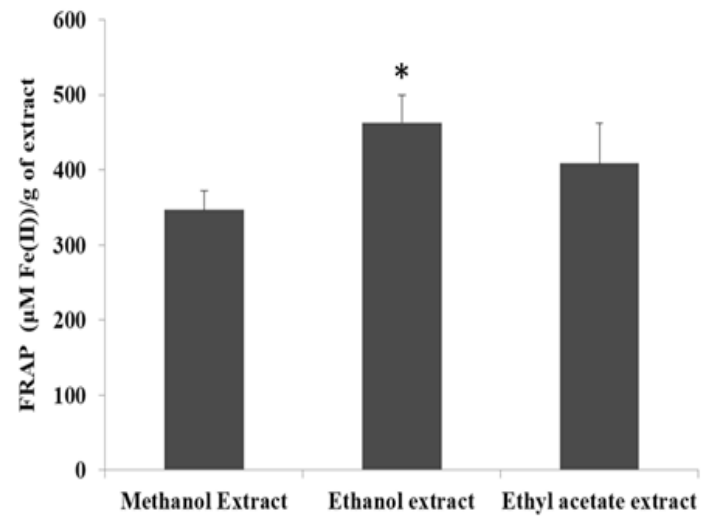

Figure 1: Total anti-oxidant activities (FRAP) of three different extracts. Results expressed as mean \pm standard deviation, $(n=3)$. All data were analyzed by ANOVA followed by Tukey post doc test. $P<0.05$ was considered as statistically significant. ${ }^{*}=P<0.05$ when compared to methanol extract
The DPPH assay (Figure 2) showed that turmeric extracts had significant radical scavenging effect with increasing concentration in the range of $20-100 \mu \mathrm{g} / \mathrm{ml}$. The maximum percentage inhibition of gallic acid, methanol, ethanol and ethyl acetate extract at $100 \mu \mathrm{g} / \mathrm{ml}$ was $87 \pm 1.73$, $72 \pm 4,74 \pm 3.24$ and $66.1 \pm 3.7$ respectively. Ethanol and methanol extract shows almost similar percentage inhibition followed by ethyl acetate extracts. The effective concentration $\left(\mathrm{EC}_{50}\right)$ of gallic acid, ethanol, methanol and ethyl acetate extract was found to be $27 \mu \mathrm{g} / \mathrm{ml}, 30 \mu \mathrm{g} / \mathrm{ml}$, $38 \mu \mathrm{g} / \mathrm{ml}$ and $47 \mu \mathrm{g} / \mathrm{ml}$ respectively in DPPH assay (Table 3 ). The ethanol extracts shows the maximum $\mathrm{EC}_{50}$ when compared to other extracts.

The $\mathrm{H}_{2} \mathrm{O}_{2}$ scavenging activity of the extract $(20,40,50,100$ and $200 \mu \mathrm{g} /$ $\mathrm{ml}$ ) was increased in a dose dependent manner and ethanol extracts found superior hydrogen peroxide scavenging activity similar to gallic acid standard as shown in Figure 3. The $\mathrm{EC}_{50}$ of gallic acid, ethanol, methanol and ethyl acetate extract was found to be $35 \mu \mathrm{g} / \mathrm{ml}, 42 \mu \mathrm{g} / \mathrm{ml}$, $53 \mu \mathrm{g} / \mathrm{ml}$ and $64 \mu \mathrm{g} / \mathrm{ml}$ respectively in $\mathrm{H}_{2} \mathrm{O}_{2}$ Scavenging assay. (Table 3 )

Figure 4 shows the Thin Layer Chromatography of turmeric extracts. (Curcuminoids and turmeric extracts were separated in TLC.) Curcuminoids were separated into curcumin, dimethoxycurcumin, bis demethoxycurcumin with $\mathrm{R}_{f}$ value of value at $0.91,0.65,0.44$ respectively. The ethanol and ethylacetate extracts $R_{f}$ value was $0.9,0.63$, 0.42 and $0.91,0.42,0.44$ respectively. Similarly, the $\mathrm{R}_{f}$ value for the three spots of the three extracts were found to be methanol; 0.90, 0.63, 0.42, ethanol; $0.9,0.63,0.42$ and ethyl acetate $0.91,0.42,0.44$ respectively. The composition of turmeric extracts was consistent with the composition of curcuminiods as shown by the $\mathrm{R}_{f}$ values.

Table 3: Effective concentration $\left(\mathrm{EC}_{50}\right)$ of turmeric extracts in DPPH and $\mathrm{H}_{2} \mathrm{O}_{2}$ scavenging activity.

\begin{tabular}{ccc}
\hline Extracts & $\begin{array}{c}\text { DPPH radical scavenging } \\
\text { activity }(\boldsymbol{\mu g} / \mathrm{ml})\end{array}$ & $\begin{array}{c}\mathbf{H}_{2} \mathbf{O}_{2} \text { Scavenging } \\
\text { activity }(\mu \mathrm{g} / \mathrm{ml})\end{array}$ \\
\hline Gallic acid & $27 \pm 2.4 \mu \mathrm{g} / \mathrm{ml}$ & $35 \pm 3.3 \mu \mathrm{g} / \mathrm{ml}$ \\
Methanolic extracts & $38 \pm 3.3 \mu \mathrm{g} / \mathrm{ml}$ & $53 \pm 2.8 \mu \mathrm{g} / \mathrm{ml}$ \\
Ethanolic extracts & $30 \pm 2.8 \mu \mathrm{g} / \mathrm{ml}^{*}$ & $42 \pm 3.4 \mu \mathrm{g} / \mathrm{ml}^{*}$ \\
Ethylacetate extracts & $47 \pm 1.9 \mu \mathrm{g} / \mathrm{ml}$ & $64 \pm 3.6 \mu \mathrm{g} / \mathrm{ml}$ \\
\hline
\end{tabular}

Results expressed as mean \pm standard deviation, $(n=3)$. All data were analyzed by ANOVA followed by Tukey post hoc test. $P<0.05$ was considered as statistically significant.

${ }^{*}=P<0.05$ when compared to methanol extract

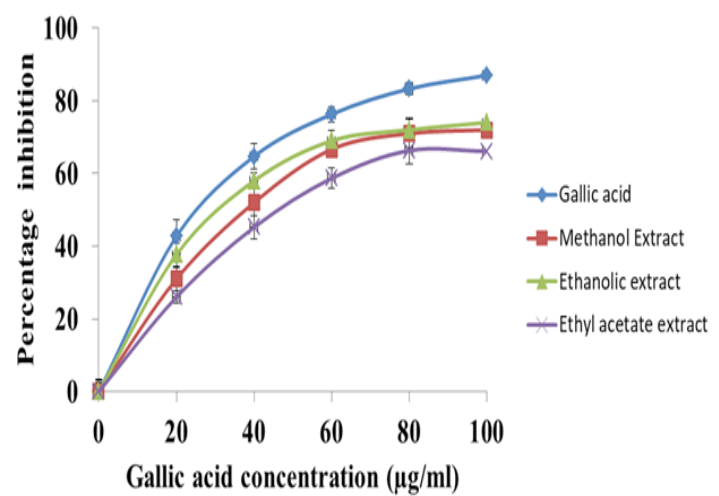

Figure 2: Graphical representation of DPPH radical scavenging activity of turmeric extracts.

Results expressed as mean \pm standard deviation, $(n=3)$. 


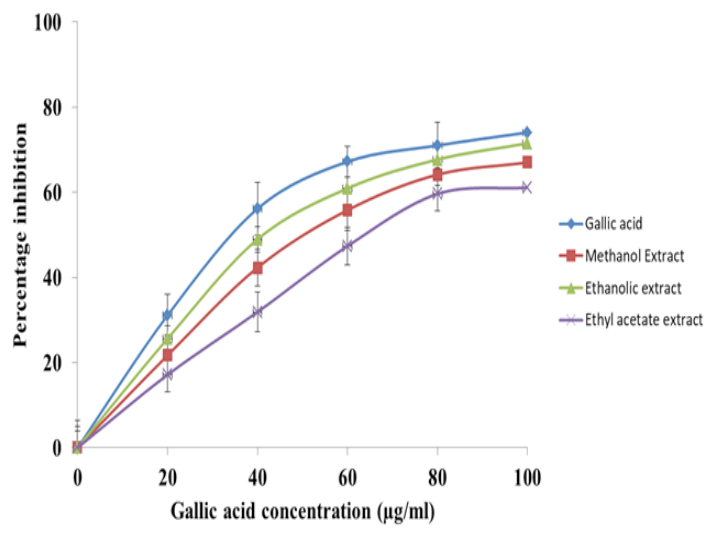

Figure 3: $\mathrm{H}_{2} \mathrm{O}_{2}$ Scavenging assay of turmeric extracts. Results expressed as mean \pm standard deviation, $(n=3)$.

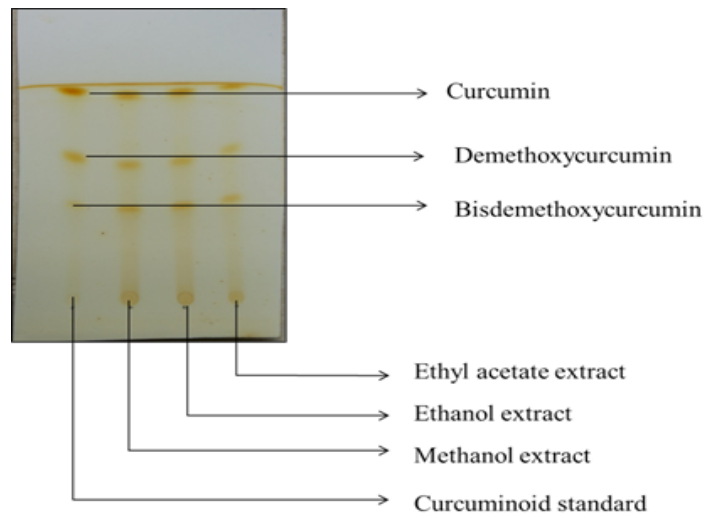

Figure 4: Thin Layer Chromatography of turmeric extracts.

\section{DISCUSSION}

In the present study, we investigated the free radical scavenging activities and antioxidant potentials of methanol, ethanol and ethyl acetate extracts of turmeric rhizome. The antioxidant properties of turmeric are attributed due to the presence of curcumin, demethoxycurcumin, bisdemethoxycurcumin and various other phytochemicals. The chemical properties and polarities of phytochemicals may vary from each other and hence soluble in different organic solvents. Hence we used three solvents; ethanol, methanol and ethyl acetate for extraction of turmeric rhizomes. Our findings indicate that the ethanolic extract of turmeric rhizome exhibited highest antioxidant activity.

The percentage extraction yield of turmeric with methanol, ethanol and ethyl acetate was found to be 10.0, 10.4 and 9.7 respectively. The yield was more likely similar with all the three solvents. Preliminary phytochemical analyses were performed in the three turmeric extracts. The presence of sterols, alkaloids, phenols, flavonoids and glycosides were observed in all the three extracts. Phenols and flavonoids were known to possess potential antioxidant properties and have major role as free radical scavengers. ${ }^{11}$ Tannin, secondary metabolite having antimicrobial, astringent and antioxidant properties was present in both methanol and ethanol extracts but absent in ethyl acetate extract. ${ }^{12}$

The extracts were analyzed for total polyphenol and flavonoid content. We found highest phenolic content and flavonoid content in the ethanol extract followed by methanol and ethyl acetate extracts. The results were supported by Tanvir et al. in which highest total flavonoid content was found in the ethanolic extract of turmeric extracts (9.66\%) when compared to aqueous extract $(0.29 \%) \cdot{ }^{13}$ Plant polyphenols are plant derived secondary metabolites, act as free radical scavengers and singlet oxygen quenchers. ${ }^{14}$ The polyphenols are further classified into flavonoids, stilbenoids and phenolic acids and flavonoids are predominant among the three groups. ${ }^{15}$ Flavonoids are natural antioxidants prevents the generation of oxidants even at low concentration by reacting with pro-oxidants leading to inactivation. Studies have shown that the antioxidant properties of polyphenols prevent oxidative stress mediated complications and there by minimize the development of diabetes, cardiovascular diseases, cancers and neurodegenerative diseases. ${ }^{11,16}$ Hence it is beneficial in alleviating many complications associated with various diseases such as diabetes, cardiovascular disease, cancer and many auto-immune disorders. ${ }^{17}$

Total antioxidant activity was used to estimate the antioxidant status in any biological sample and the advantage of the test is it measures all antioxidants and not the activity of a single compound. ${ }^{10}$ The ethanol extract of turmeric exhibited significantly higher antioxidant activity when compared to methanol and ethyl acetate extracts of extract.

The free radical scavenging activity of turmeric extracts was assessed by Diphenyl- $\beta$-picrylhydrazyl (DPPH) assay. It is extensively used to assess the free radical scavenging and the hydrogen donating ability of the test compound. ${ }^{13}$ The DPPH assay showed that turmeric extracts had significant radical scavenging effect with increasing concentration in the range of $20-100 \mu \mathrm{g} / \mathrm{ml}$. The ethanol extract shows the maximum $\mathrm{EC}_{50}$ when compared to other extracts. The high anti-oxidant activity of turmeric extract is due to presence of phytochemicals such as phenols, flavonoids, anthocyanins and curcuminoids. The curcuminoids include curcumin, dimethoxycurcumin and bis demethoxycurcumin among them curcumin has the highest anti-oxidant property which is attributed to its methoxylated phenols and $\beta$ - diketone structure. ${ }^{18,19}$ In our study, $\mathrm{H}_{2} \mathrm{O}_{2}$ scavenging activity of the extracts have shown that ethanol extract showed superior hydrogen peroxide scavenging activity similar to gallic acid standard. The $\mathrm{EC}_{50}$ of ethanol was found to be $42 \mu \mathrm{g} / \mathrm{ml}$ in $\mathrm{H}_{2} \mathrm{O}_{2}$ Scavenging assay. These findings were in line with the previous study in which ethanolic extract showed higher $\mathrm{EC}_{50}$ values when compared to other extracts. ${ }^{20}$

Consistent with this we have analyzed the different curcuminoids by thin layer chromatography (TLC) for all the three extracts. The $\mathrm{R}_{f}$ value of all the three turmeric extracts was consistent with the composition of standard curcuminiods. In recent years use of alternative therapeutic approaches has been explored. Naturally derived potent polyphenols from plant sources may be used to alleviate several metabolic complications with minimal adverse effects. Curcumin (diferuloly-methane) is the active component derived from Curcuma longa. Curcumin is a potent scavenger of ROS and nitrogen dioxide radicals. ${ }^{19}$ Studies also have shown that curcumin exhibits strong antioxidant activity and play a vital role against oxidative stress mediated diseases like diabetes, obesity and cardiovascular diseases. ${ }^{21}$

\section{CONCLUSION}

In the present study, we estimated the free radical scavenging activities and antioxidant properties of turmeric rhizomes using methanol, ethanol and ethyl acetate. The preliminary phytochemical screening of the turmeric extracts showed the presence of vital constituents such as sterols, alkaloids, flavonoids, phenols and tannins. The total polyphenol and flavonoid content of the ethanolic extract was higher when compared with the other extracts. The ethanolic extract also displayed higher antioxidant activity by FRAP assay. On comparison with other extracts, ethanol extract of turmeric exhibited greater free radical scavenging activity and antioxidant property. 


\section{ACKNOWLEDGEMENT}

We thank JIPMER and Mahatma Gandhi Medical College and Research Institute (MGMCRI) for providing the infrastructure required for the study.

\section{CONFLICT OF INTEREST}

The authors declare no conflicts of interest.

\section{ABBREVIATIONS}

DPPH: 2, 2-Diphenyl-1-Picrylhydrazyl DPPH; TLC: Thin layer Chromatography; TPTZ: 2, 4, 6-tripyridyl-s-triazine; FRAP: Ferric Reducing Antioxidant Power Assay; $\mathbf{H}_{2} \mathbf{O}_{2}$ : Hydrogen peroxide; EC: Effective concentration; GAE: Gallic acid equivalents; QE: Quercetin equivalents; RF: Retention factor.

\section{REFERENCES}

1. Chattopadhyay I, Biswas K, Bandyopadhyay U, Banerjee RK. Turmeric and curcumin: biological actions and medicinal applications. Curr Sci. 2004;87:44-53.

2. Indian Medicinal Plant by KR Kirtikar BD Basu-AbeBooks. 2019. https://www. abebooks.com/book-search/title/indian-medicinal-plant/author/k-r-kirtikar-b-dbasu/.

3. Jurenka JS. Anti-inflammatory properties of curcumin, a major constituent of Curcuma longa: A review of preclinical and clinical research. Altern Med Rev J Clin Ther. 2009;14(2):141-53.

4. Rahmani AH, Alsahli MA, Aly SM, Khan MA, Aldebasi YH. Role of Curcumin in Disease Prevention and Treatment. Adv Biomed Res. 2018;7:38.

5. Hosdurga R, Rani SN, Prathima MSK, Chandrashekar REPR. Phytochemical analysis of Methanolic extract of Curcuma longa Linn. Int J Univers Pharm Biosci 2319-8141. 2013;2:39-45.

6. Singleton VL, Rossi JA. Colorimetry of Total Phenolics with PhosphomolybdicPhosphotungstic Acid Reagents. Am J Enol Vitic. 1965;16(3):144-58.
7. Sulaiman CT, Balachandran I. Total Phenolics and Total Flavonoids in Selected Indian Medicinal Plants. Indian J Pharm Sci. 2012;74(3):258-60.

8. Bozin B, Mimica-Dukic N, Samojlik I, Goran A, Igic R. Phenolics as antioxidants in garlic (Allium sativum L., Alliaceae). Food Chem. 2008;111(4):925-9.

9. Brand-Williams W, Cuvelier ME, Berset C. Use of a free radical method to evaluate antioxidant activity. LWT - Food Sci Technol. 1995;28(1):25-30.

10. Benzie IF, Strain JJ. The Ferric Reducing Ability of Plasma (FRAP) as a measure of "antioxidant power": The FRAP assay. Anal Biochem. 1996;239(1):70-6.

11. Pandey KB, Rizvi SI. Plant polyphenols as dietary antioxidants in human health and disease. Oxid Med Cell Longev. 2009;2(5):270-8.

12. Maisetta G, Batoni G, Caboni P, Esin S, Rinaldi AC, Zucca P. Tannin profile, antioxidant properties and antimicrobial activity of extracts from two Mediterranean species of parasitic plant Cytinus. BMC Complement Altern Med. 2019;19(1):82.

13. Sepahpour S, Selamat J, Abdul MMY, Khatib A, Abdull RAF. Comparative Analysis of Chemical Composition, Antioxidant Activity and Quantitative Characterization of Some Phenolic Compounds in Selected Herbs and Spices in Different Solvent Extraction Systems. Mol J Synth Chem Nat Prod Chem. 2018;23(2):E402.

14. Cook NC, Samman S. Flavonoids-Chemistry, metabolism, cardioprotective effects and dietary sources. J Nutr Biochem. 1996;7(2):66-76.

15. Perveen S, Al-Taweel AM. Phenolic Compounds from the Natural Sources and Their Cytotoxicity. Phenolic Compd - Nat Sources Importance Appl. 2017.

16. Pandey KB, Rizvi SI. Protective effect of resveratrol on markers of oxidative stress in human erythrocytes subjected to in vitro oxidative insult. Phytother Res PTR. 2010;24 (Suppl 1):S11-4

17. Yao LH, Jiang YM, Shi J, et al. Flavonoids in food and their health benefits. Plant Foods Hum Nutr Dordr Neth. 2004;59(3):113-22.

18. Masuda T, Maekawa T, Hidaka K, Bando H, Takeda Y, Yamaguchi H. Chemical Studies on Antioxidant Mechanism of Curcumin: Analysis of Oxidative Coupling Products from Curcumin and Linoleate. J Agric Food Chem. 2001;49(5):2539-47.

19. Sreejayan N, Rao MN. Curcuminoids as potent inhibitors of lipid peroxidation. $J$ Pharm Pharmacol. 1994;46(12):1013-6.

20. Qader SW, Abdulla MA, Chua LS, Najim N, Zain MM, Hamdan S. Antioxidant, Total Phenolic Content and Cytotoxicity Evaluation of Selected Malaysian Plants. Molecules. 2011;16(4):3433-43.

21. Na LX, Zhang YL, Li Y, et al. Curcumin improves insulin resistance in skeletal muscle of rats. Nutr Metab Cardiovasc Dis NMCD. 2011;21(7):526-33.

Article History: Submission Date : 17-10-2019; Revised Date : 06-11-2019; Acceptance Date : 10-12-2019.

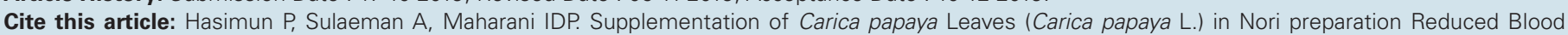
Pressure and Arterial Stiffness on Hypertensive Animal Model. J Young Pharm. 2020;12(2):113-7. 